\title{
La Casa de la Universidad de San Marcos en el Siglo XVII
}

Mal año fué el de 1687 para los limeños porque vivieron en el temor y sobresalto más agudos desde el mes de febrero, en que estuvo la capital del Virreynato a punto de caer en las manos codiciosas del pirata flamenco Eduardo David, que la huoiera saqueado y humillado sin tasa; hasta el 20 de Octubre, en cuyo trágico amanecer un terremoto destrozó Lima, dejándola "desquadernada y dividida", sin edificio bueno libre de escombros.

Uno de los duramente castigados por el sismo fué el de la Real Universidad de San Marcos, cuyo local estaba situado en la plazuela de la Inquisición, al costado del hospital de la Caridad, en el solar que le diera más de cien años antes el Virrey Don Francisco de Toledo. El sitio corresponde hoy al palacio del Congreso.

Gobernaba a la UUniversidadccomoi Rectoreleb Doctor D. Diego de León Pinelo Gutiérrez, Racionero de la Catedral y canonista insigne, miembro de la notable familia marrana de los León Pinelo, que tanta gloria diera a las letras indianas de aquel siglo. Hombre de extraordinaria actividad, acometió la obra de levantar nuevamente la casa universitaria a menos de dos meses del terremoto. El 17 de Diciembre reunió al Claustro y se dió comisión a los Doctores D. Francisco Ignacio de la Daga y Vargas y Padre Maestro fray Josøph Barraza, mercedario, Rector del Colegio de San Pedro Nolasco, y al Procurador D. Jerónimo de los Reyes, para que reconocieran la ruina y daños ocasionados por los temblores y buscaran el aderezo y reparo que necesitase el local.

Los comisarios recurrieron a un célebre arquitecto asistente en Lima, el padre fray Diego Maroto, dominico, para que levantara su informe técnico. Maroto hacía muchos años que venía ejerciendo en Lima como Maestro Mayor de Fábricas y el terremoto acababa de consagrar su buena fama pues de todos los templos tan sólo había quedado 
en pié, sin mayor daño, la capilla del Sagrario, que construyera en 1665, al punto de poder servir para la celebración de los divinos oficios mientras la Catedral y las demás iglesias quedaban arruinadas (')

Fray Diego Maroto vió y reconoció el sitio de la Universidad el 22 de Diciembre, paseándolo en compañía de los Doctores D. Pedro de Astorga y Figueroa, Catedrático de Prima de Sagrados Cánones, Procurador General, y de D. Aqustín de Baños y Vivar, Tescrero y Administrador de sus bienes, emitiendo luego una memoria minuciosa. Consideramos que es un documento de suma importancia para la historia de San Marcos y merece darse a luz íntegramente, pues con los datos que encierra podrán los historiadores del claustro, los expertos en arte virreynal y los arquitectos, de consuno, reconstruir el verdadero plano de la Casa tal como fuera durante el siglo XVII, en cuyas venera. bles paredes latiera la voz de los grandes canonistas, juristas y gramáticos de aquella época tan colmada de nombres.

\section{INFORME DEL ARQUITECTO FRAY DIEGO MAROTO}

'CALLE: La Pcrtada Principal se a de hacer de buen ladrillo y mescla de cal y Arena y los pedestales de las pilastras se han de acabar de moler hasta buscar simientos y esos se han de añadir por la parte de afuera tres quartas mas y de fondo hastalel cascaxo llenandolo de piedra del Rio caloygarenacmesclada devtres (y dos de cal y encima se han de volver a formar las Pilastras de dos ladrillos de ancho con dos relaltos de a ochava asia la parte de las hambras y a la parte de atrás relaltos y dhas hambras han de ser de un ladrillo y medio de grueso con sus basas de plinto fileton y media caña y con capiteles alquitrabe frisso y cornisa de cinco q. tenga media vara de grueso y algo mas y ensima un segundo cuerpecillo con sus pilas trillas y sus capiteles con su arquillo que tenga de fondo medio ladrillo para fixar las armas dentro con su frontis ensima y sus argotantes a los lados de ladrillo y pedestalillo en medio con su Cruz dejandola enlussida y dado color.

"La pared de la calle de la plazuela desde la puerta prinl. hasta pasada la puerta de asia la hotica una hara mas se ha de calsar de

('ג P. Vargars Ugarte S. J.: Ensayo de un diccionario de Artífices coloniales etc., Buenos Aires, 1947, p. 195. 
vara y media de alto de todo el gruesso de la Pared de piedra y cal las caras con piedra del Cerro y en medio piedra del Rio y por de fuera se ha de coger el plomo desde dos varas de alto y la puerta de la Casa del Secretario se a de haser de ladrillo y cal, los pilares də bara de ancho con su arco cuaxado y de grueso lo que time la pared con su imposta encima de dos hiladas boladas un doseabo y bolber a hacer la adobería de ensima enlusida y dado color. Y de la puerta prinl. para la Capilla que hay de pared vieja como doze baras de largo se ha de rebajar hasta el alto de las maderas del entresuelo para q. quando se haga la Capilla de nuebo la pared y todo lo que quedare en pie de la fachada q. se ha de poner a nivel conforme al alto del Saguan con su cexa bolada se han de remendar los enlusidos y cantearlos q. quede aseado.

"SAGUAN. En el Saguan prinl. se han de afixar todas las raxaduras y aderesar los enlusidos y ensusiarlo todo y volberlo a cantear de nuevo y en el techo estan rotos res quartoncillos en la lumbre de en medio y otro en otra lumbre antecedente $y$ se han de volber a poner sus tablas ensima.

SECRETARIA. Entrando en la primera pieza de la Secretaria en la pared de mano izquierda en lo alto del rincon se ha de desbaratar como cien adobes y el otro rincon de la misma pared como cinquenta y afixar todas las raxaduras yu enlusir todonlo maltratado y volberlo a blanquearlo $Y$ en la puerta qe. entra a la bibienda a la mano isquierda se ha de meter un pilar de ladrillo de todo el grueso de la pared y de ancho de mayor de dos ladrillos y medio comensandolo asi y de menor de dos ladrillos hasta resevir los umbrales y de dha segunda piosa se ha caido el techo y quebrado cinco quartones que se han de volber a poner algo mas gruesos qe. los otros q. han quedado y enstma texer su caña braba limpia y expesa y estera y torta de barro amasada con paxa. Y la pared de frente se ha de bolber a lebantar hasta el alto de dho techo enlusir y blanquear todo lo maltratado. $Y$ en el primer aposento de la vibienda se a de quitar las cintas qe. tiene de madera y poner cañas limpias y esteras espesas su torta de barro amasada con paja. $Y$ en el segundo aposento está un mangle qe. le falta al techo se a de poner y sus cañas y esteras y la pared qe. linda con la Charidad está cayda un pedaso qe. se a de volber a lebantar y enlusir y blanquear ambas piezas. 
"GENERAL DE ARTES DEL SAGUAN. Se ha de fixar por las raxa. duras y enlusir lo maltratado y blanquearlo.

"GENERAL DE CANONES. Las dos paredes de las testeras se han de vajar tres varas y media de alto abajo cada una en todo su ancho de nuebe varas y mas las trabasones de las paredes de los lados y en la puerta al lado de mano isquierda se ha de hacer un pilar de ladrillo de todo el grueso de la pared y de ancho de mayor bara y sexma y de menor una bara y volberlas a lebantar acompañando las maderas y fixar las raxaduras y enlusir lo qe. se hiciere y lo maltratado y todos los enlusidos sobre adobe han de ser de tierra y arena y blanquear dho. Genl.

"GENERAL SEGUNDO DE ARTES. La pared de la entrada qe. es la de la puerta qe. tiene ocho baras y media con el un grueso y de alto siete baras poco mas o menos hasta ensima de las maderas se a de derribar y bolber a hacer del mismo grueso y alto y enlusirlo por de dentro y fuera y fixar las raxaduras y aliñar los enlusidos y blanquearla toda desbaratando hastta la mitad de su alto y volbiendola a hacer.

"GENERAL TERZERO DE ARTES. La pared de la puerta se ha de desbaratar hasta el suelo y de largo hasta el Arco argotante del Claustro y volberla a hacer enlusir yl blanquear comor también la pared de la testera de lo alto se a de quitar tres baras y bolberla a hacer dexando dos guecos de bara y media de largo y una de ancho con sus derrames por adentro y enlusir y blanquiar y afixar las raxaduras de dha piesa y blanquearla.

"GENERAL DE SANTO DOMINGO. Esta maltratado el techo y caldo muchos quartones y tablas qe. son trece los quartonsillos y se han de bolber a poner y entablar ensima con su torta de barro y afixar en todas las raspaduras de las paredes (sic) y enlusir lo maltratado y blanquiarlo.

"ESCALERA POR DONDE SE SUBE A LAS TRIBUNAS. Esta caida la ultima ida en qe. habia catorce escalones y eran de adobe los osinos sobre qe. cargaban y se a de hacer un pilar de ladrillo de dos ladrillos de grueso arimado a la puerta qe. sale al Claustro del ancho de 
la escalera y otro del mismo grueso en la mitad de la distancia para deducir a dos osinos hasiendolos de ladrillo y cal y ensima de ellos los escalones; y asimismo sobre dhos osinos ha de lebantar el tabique de adobe qe. antes estaba hasta el techo; y asimismo la puerta que. sale al Claustro se ha de derribar toda la testera del corredor en qe. esta y bolber a hacerla hasiendo dos pilares de ladrillo y cal y su arquillo ensima revaxado $y$-ensima del proseguir de adoberia hasta enratar con el cubierto de dho patio.

"GENERAL DE TEOLOGIA. Es necesario en el un lado de la bentana qe. esta junto a la Cathedra un pilar de ladrillo desde el suelo qe. tendra tres baras y tercia de bara en quadro de grueso con sus travasones y en la otra bentana otro pilar del mismo tamaño y la pared de frente bajarla dos baras en lo alto y bolberlas a hacer y alsaprimar las dos madres qe. se han baxado y enlusir y acuñar las hendiduras de todo y remendar los enlusidos y blanquear y poner tablas qe. faltan al techo y la solera y tabica.

"ClaUstro.' En el Claustro prinl. qe. tiene diez y seis pilares los dos de ellos desde el General de Canones a la Sacristia estan los Capiteles molidos y es necesario apuntalarlos y suspender los arcos de ensima y volbera hacer dhos capiteles con ladrillos pasteleros bien cosidos y asentados con Yeso de la sierra. Y asimismo afixar todas las rajaduras de las claves délos demasvarcos"como tambien las de las paredes de la caxa del Claustro y enlusir todo lo descostrado y labarlo canteado y bolberlo a cantear todo de nuebo como tambien los pilares y encima lebantar un antepecho de adobe chico tres quartas de alto sobre los techos y sobre este antepecho hechar dos hiladas de ladrillo y cal voladas una ochava y enlusidas, y dhos arcos se han de volber a renobar lo canteado de ladrillejo como hasta hoy. Y por necesitar de muchos puntales largos qe. costara trabajo el hallarlos se añaden doscientos ps. mas a esta partida.

"GENERAL SECRETO Y MAYOR. Las paredes de la Sala prinl. qe. es de beinte y ocho baras de gueco su largo, estan desplomadas son de adoberia material debil y volberlas a hacer de lo mismo quedamos sugetos quiza a mayor ruina qe. la presente. $Y$ asi he adbertido sin comparasion ser mejor se hagan en cada una cinco arcos de ladrillo y cal qe. seran de a quatro baras cada uno y de alto hasta re- 
cibir las maderas de los segundos Canes acompañados dhos Arcos por encima al nivel del grueso de ellos y los Pilares han de tener el grueso de la Pared y de ancho los de los extremos dos baras y sexma y buelba con la misma anchura a abrazar las testeras y los quatro pilares de la mediannía han de ser del mismo grueso de la pared y de dos baras de ancho de mayor y de menor bara y dos tercias de dho ancho y las roscas de los Arcos han de ser de dos ladrillos de Peralte y de grueso toda la pared y el acompañant ${ }^{\circ}$ de ensima de ladrillo a nivel con lo bajo de la clave y el resto de ensima qe. es el acompañamt? de los Canes y vigas sera de adobe qe. es a donde no trabaxa la gravedad y peso de las maderas como tampoco de la Pared porqe. esto cae en lo alto, conque. quedaran mui seguras las dos salas. Y se adbierte qe. las mesclas para toda la Obra de ladrillo y piedra han de ser de dos Capachos de Cal y tres de arena, y los enlusidos para dha obra de cal y arena y para la obra de adobe de arena y tierra y ha de quedar todo acabado con perfeccion y arte.

"CAPILLA Y SACRISTIA. La Capilla y Sacristia se reserva $\equiv 1$ hacerse para mejor ocasion por no haber materiales $y$ se podra poner en un General".

\section{Biblioteca de Letras}

Fray Maroto acompañó su informe con un mapa y modelo que no conocemos, pues el texto reproducido es el que corre intercalado en el acta de remate de la obra ('), que tasó el sabio dominico en 10.530 pesos de a ocho reales el peso.

Del 3 al 7 de Enero el negro Sebastián Villegas pregonó nueve veces, según ley, la licitación, saliendo de postores Francisco Ximenez, Maestro albañil y Alarife de esta ciudad, con 11.250 pesos, y el capitán Joseph de Robles, con 11.000.

El 10 de Enero de 1688, a las doce del día y en la puerta de la escribanía pública de Francisco Sánchez Becerra, situada en la plaza Mayor de Lima, en presencia del Rector de la Universidad, comisarios de la obra, Catedráticos y numeroso concurso de gentes, empezó el remate Francisco Ximenez con 10.900 pesos, siguiéndole Juan Iñigo de Erazo, Maestro albañil, con 10.800, quedando por fin la obra en manos

(') Archivo Nacional del Perú, protoc. F. Sánchez Becerra, 1688, fs. 99-109v. 
de Ximenez que bajó hasta 10.750 pesos de a ozho rəales cada peso. Las condiciones eran dar acabada la obra y $\cong n$ toda perfezción sexún el mapa y modelo de Maroto, al fin de dos años contados desde aquel día. siempre que el materia'l se pusiera en los patios de la Universidad, y en caso que pasados aquellos dos años no la hubiera terminado Ximenez pagaría una multa de 500 p $\triangleq s o s$ descontables del precio total. Este solo sería pagado al concluir el trabajo, que Ximenez se obligaba a mostrar toda vez que el Rector y comisarios de la obra lo demandaran, y si a juicio de ellos alguna parte no era conforme con la memoria de fray Diego Maroto derribaríase y empezaría otra vez a costa de aquel.

El rematista no podía percibir otro dinero hasta el final de su contrato que el correspondiente a semanas de peones, jornales y materiales, para lo cual quedaba autorizado el Mayordomo y Tesorero de la Universidad, previa la expedición de las correspondientes cartas de pago.

Francisco Ximenez, Joseph de Róbles y Juan Iñigo de Erazo, Maestros albañiles y Alarifes de Lima, eran hasta hoy tres nombres desconocidos que no figuraban en el catálogo de los artífices del Perú virreynal.

\section{Biblioteca de Jorge Zevallos Quiñones. "Jorge Puccinelli Converso»}

